\title{
Microbial etiologies of ventilator-associated pneumonia (VAP) in intensive care unit of Beni-Suef University's Hospital
}

\author{
Al Zahraa M. Maebed', Yasser Gaber ${ }^{2,3}$, Walid Bakeer $^{2}$ and Tarek Dishisha ${ }^{2 *}$
}

\begin{abstract}
Background: Ventilator-associated pneumonia (VAP) is a major health problem for people intubated in intensive care units (ICUs), leading to increased mortality rates, hospital stay, and treatment costs. In the present study, the core pathogens causing VAP in Beni-Suef University's Hospital, Egypt, was investigated over a study period of 2 years (2017-2019).
\end{abstract}

Results: Of a total of 213 patients subjected to mechanical ventilation, 60 have developed VAP during their stay in the ICU. The mortality rate reached $41.7 \%$ among VAP patients. Sixty bacteria were isolated from an endotracheal aspirate of hospitalized patients. The different isolates were cultured followed by running biochemical tests, sensitivity assays, and automated VITEK ${ }^{\circledR} 2$ System analysis. Unexpectedly, all the isolates were Gram-negative bacteria. Klebsiella pneumoniae were the main pathogen encountered (27/60 isolates) followed by Acientobacter baumannnii (7/60) and other microorganisms belonging to the genera Moraxella, Escherichia, and Pseudomonas (11/ 60). Antibiotic sensitivity testing was performed via the VITEK ${ }^{\circledR}$ System using up to 16 different antibiotics representing 8 different antibiotic classes and subclasses (aminoglycosides, carbapenems, fluoroquinolones, penicillin/ $\beta$-lactamase inhibitor, extended-spectrum cephalosporins, aminopenicillins, aminopenicillins/ $\beta$-lactamase inhibitor, folic acid synthesis inhibitor). Majority of the isolates (28/60) showed a remarkable extensive drug resistance (XDR) pattern, while 15 isolates were multi-drug resistant (MDR) and only 6 were pan-drug resistant (PDR) with regard to antibiotics under evaluation.

Conclusion: The association of VAP with multi-drug-resistant bacteria is alarming, and rapid management is crucial. Identification of core pathogens is essential for identifying the most appropriate technique for infection control.

Keywords: Ventilator-associated pneumonia, VAP, Intensive care unit, Pathogens, Klebsiella pneumoniae, Acinetobacter baumanii, Antibiotic sensitivity testing

\section{Background}

Ventilator-associated pneumonia (VAP) is a complication of nosocomial infection that occurs in patients receiving mechanical ventilation for more than $48 \mathrm{~h}$, mainly in intensive care units $[1,2]$. It is associated with an increased incidence of morbidity and mortality, longtime admission to hospitals, and increased treatment

\footnotetext{
* Correspondence: Tarek.Dishisha@pharm.bsu.edu.eg

${ }^{2}$ Department of Microbiology and Immunology, Faculty of Pharmacy,

Beni-Suef University, Beni Suef, Egypt

Full list of author information is available at the end of the article
}

costs [3]. The mortality rate attributable to VAP was reported as $27 \%$ and can reach as high as $43 \%$ with antibiotic-resistant organisms [4]. Two different forms of VAP have been reported [5], the early-onset VAP that occurs 48-96 h after intubation and the late-onset VAP that occurs more than $96 \mathrm{~h}$ after intubation. The former is associated with antibiotic-susceptible microorganisms including Staphylococcus aureus, Streptococcus pneumoniae, and Haemophilus influenzae, as well as Gramnegative enteric bacilli. While the latter occurs with antibiotic-resistant organisms including methicillin-

\section{Springer Open}

(- The Author(s). 2021 Open Access This article is licensed under a Creative Commons Attribution 4.0 International License, which permits use, sharing, adaptation, distribution and reproduction in any medium or format, as long as you give appropriate credit to the original author(s) and the source, provide a link to the Creative Commons licence, and indicate if changes were made. The images or other third party material in this article are included in the article's Creative Commons licence, unless indicated otherwise in a credit line to the material. If material is not included in the article's Creative Commons licence and your intended use is not permitted by statutory regulation or exceeds the permitted use, you will need to obtain permission directly from the copyright holder. To view a copy of this licence, visit http://creativecommons.org/licenses/by/4.0/. 
resistant S. aureus (MRSA), Pseudomonas aeruginosa, Acinetobacter baumannii, and Stenotrophomonas maltophilia $[3,6]$.

Different reasons stand behind the development of VAP. Initially, the ventilator tracheal tube bypasses the upper airway and facilitates the entry of the bacteria to the lower airway and hence reduces the body's ability to filter and humidify the air [7]. Additionally, the significant reduction of the cough reflex and impairment of muco-ciliary clearance caused by mucosal injury during intubation increases the chances of microbial infection. The endotracheal tubes also make it easier for the attachment of bacteria to the trachea and hence increases mucus production [8].

The association of VAP with the multi-drug-resistant bacteria in intensive care units (ICUs) has further complicated the situation worldwide [9]. Hence, the development of novel antimicrobials for preventing and/or treating the resulting infections is a necessity. For achieving this, the first step is always the identification of the main causative agents and their resistance pattern. This will facilitate the choice of the proper technique for infection control among the available antimicrobial strategies including antimicrobial peptides (bacteriocins) and enzymes (enzybiotics), predatory bacteria, bacteriophages, and bacteriophage-derived proteins that are considered potential alternatives to conventional antibiotics in the post-antibiotic era, called by the WHO $[10,11]$.

Therefore, the objective of the current study is to identify the core pathogens causing VAP at Beni-Suef University's (BSU) Hospital which is a public, free hospital operated by the Faculty of Medicine, BSU. The different isolates will be examined for drug resistance pattern against a panel of different antibiotics representing different classes.

\section{Methods}

\subsection{Materials and culture media}

Blood agar and chocolate agar were procured from HiMedia Laboratories Pvt. Ltd. (Mumbai, India), MacConkey agar from Condalab (Madrid, Spain), and Triple Sugar Iron (TSI) Agar from MAST group Ltd. (Merseyside, UK), and Simmon's Citrate Agar was obtained from Ltd. (Lancashire, UK). LB agar was prepared in the lab using peptone (Oxford, India), yeast extract (Lab M Limited, UK), $\mathrm{NaCl}$ (Biotech, Egypt), and Agar-Agar (B\&V Ltd., Italy).

\subsection{Study design}

This observational, prospective incidence study was undertaken for a 2-year period from mid-2017 to 2019 in the General ICUs of the BSU Hospital, Egypt. Enrolled cases were selected from patients admitted to the emergency ICU with different causes of admission, and the number of days of ventilation and ICU stay was recorded. Only patients that were mechanically ventilated for more than $48 \mathrm{~h}$ were considered, excluding the ones having previous evidence of chest infection prior to intubation.

The choice of VAP cases was based on 6 clinical and laboratory criteria: temperature, leukocyte count, volume and purulence of tracheal secretions, oxygen level, chest radiographic findings, and the presence or absence of positive endotracheal aspiration cultures as described earlier for the diagnosis of VAP [12]. Once VAP was clinically diagnosed using clinical or radiological criteria or a combination of both, the specimen was collected by the critical care physician on duty using an aseptic technique. Overall, 60 samples were collected from the endotracheal aspirate.

\subsection{Isolation of VAP pathogens}

The different isolates were examined microscopically using the Gram-staining technique, then samples were transferred to blood agar, chocolate agar as enriched media, and MacConkey agar as selective and differential media, and the plates were incubated at $37^{\circ} \mathrm{C}$ for $48 \mathrm{~h}$.

\subsection{Bacterial identification and antibiotic susceptibility testing using the $\mathrm{VITEK}^{\oplus} 2$ system}

The $\operatorname{VITEK}^{\circ} 2$ compact system (bioMérieux, Marcy l'Etoile, France) at Beni Suef, Egypt, was used for the identification of the different isolates. VITEK ${ }^{\circ} 2$ compact is an automated microbiology system for the identification of different microorganisms using colorimetric reagent cards. Each card has 64 wells, and each contains a substrate that measures a specific metabolic activity [13]. Sample preparation and operating conditions were according to the manufacturer's recommendations. The identity of some isolates was further re-confirmed by running a number of biochemical tests including the Triple Sugar Iron (TSI) test and citrate utilization.

The antibiotic susceptibility of the different isolates was determined for 16 different antibiotics belonging to 8 classes and subclasses including aminoglycosides, carbapenems, fluoroquinolones, extended-spectrum cephalosporins, aminopenicillins, aminopenicillins/ $\beta$-lactamase inhibitors, folic acid synthesis inhibitors, and glycylcyclines. The analyses were performed by the VITEK 2 system using Antibiotic Susceptibility Test (AST) cards, inoculated according to the manufacturer's guidelines.

\section{Results}

\subsection{Antibiotic-resistant VAP in BSU Hospital}

The ICU of BSU Hospital has 16 beds. During the study period, 585 patients were admitted to the ICU for different reasons; when cases get worse, they were subjected to mechanical ventilation. Overall, 213 patients were 
ventilated for more than 5 days, and 60 eligible patients have developed VAP during the study period. Table 1 presents the demographic data (age, sex), cause of entry to the ICU, days of hospital stay, days of mechanical ventilation, and VAP-causing bacteria. Unfortunately, 25 VAP patients died during the 2 years of the study. VAP incidence rate was about 28\% (60 patients of a total of 213 patients subjected to mechanical ventilation have developed VAP), and the mortality rate reached $41.6 \%$ among VAP cases.

Most of the VAP cases were males $(n=37 ; 61.6 \%)$ having a mean age of $54.83 \pm 8.40$ years (range $30-80$ years). Trauma was the main cause for ICU admission among VAP male cases, followed by liver cell failure and urinary tract infection (UTI) (Tables 1 and 2). The residual 23 patients were females having a mean age of $23.26 \pm 6.52$ years (range 25-80 years). Eclampsia and diabetic ketoacidosis were the main causes of ICU admission among female VAP cases (Tables 1 and 2).

\subsection{Identification and confirmation of bacterial isolates}

A total of $60 \mathrm{VAP}$-associated bacterial pathogens were collected during the study period. All the isolates were obtained from tracheal aspirates. The core pathogens of the VAP were isolated on different culture media: blood agar and chocolate agar as enriched media and MacConkey agar as a selective, differential medium. Most of the isolates appeared as pink colonies on MacConkey agar showing mucoid surface; however, few were black colonies expressing grape-like odor (sweet, fruity smell). The isolates obtained from all the samples were Gramnegative bacteria.

The identification of the isolates was done by the VITEK $^{\circ} 2$ system. Figure 1 presents the distribution of the infectious agents among VAP cases. Klebsiella species $(n=28 ; 46.7 \%)$ were the main responsible for VAP; 27 were identified as $K$. pneumoniae while 1 was $K$. oxytoca. Acinetobacter species $(n=10 ; 16.7 \%)$ came second including A. baumannii (7 cases), A. lwoffii (2 cases), and $A$. haemolyticus ( 1 case). The remaining cases were as follows: Moraxella group (5), Pseudomonas aeruginosa (2), Pseudomonas luteola (2), Pseudomonas putida (1), Serratia odorifera (1), Sphinogobacterium thalpophilum (2), Sphinogobacterium paucimobilis (1), Brevundimonas diminyta/vesicularis (1), Escherichia coli (1), and Enterobacter aerogenes (1).

A number of biochemical tests were conducted for confirming the identity of some isolates using the TSI test which gave acid slant and acid butt accompanied with gas production with $K$. pneumoniae while was negative with Acinetobacter being a non-fermentative microorganism. On the other hand, E. coli had similar results to K. pneumoniae accompanied with more gas production, however was negative to citrate test [14].

\subsection{Antibiotic susceptibility testing of VAP isolates}

Isolates were tested for antimicrobial susceptibility using the VITEK $^{\circ} 2$ system and partly using the modified Kirby-Bauer disc diffusion method [15]. The sensitivity of the different isolates was recorded as sensitive, medium, or resistant. Based on this evaluation, the isolates were categorized as follows: multi-drug resistance (MDR) was designated for isolates non-susceptible to at least one agent in at least three different antimicrobial categories, extensive drug resistance (XDR) for isolates non-susceptible to at least one agent in all but at maximum 2 categories, and pan-drug resistance (PDR) was used for isolates non-susceptible to all listed antimicrobial agents. This categorization was employed according to the classification made by the European Centre for Disease Prevention and Control (ECDC) and the Centre for Disease Control and Prevention (CDC) and other expert opinions [16, 17].

The antimicrobial susceptibility of $K \cdot$ pneumoniae isolates was tested against 8 different classes of antibiotics/ antibiotic combinations. These included aminoglycosides (gentamicin, tobramycin, amikacin), carbapenems (meropenem, imipenem), fluoroquinolones (levofloxacine, ciprofloxacin), penicillin/ $\beta$-lactamase inhibitor combination (piperacillin/tazobactam), extended-spectrum cephalosporins (cefepime, cefazolin, cefoxitin, ceftazidime, ceftriaxone), aminopenicillins (ampicillin), aminopenicillins/ $\beta$-lactamase inhibitor combination (ampicillin/sulbactam), and folic acid synthesis inhibitor (trimethoprim/sulfamethoxazole). The percentage antimicrobial resistance of $K$. pneumoniae isolates ranged between 67 and $96 \%$ towards tested antibiotics. Most of the isolates showed multi-drug and extensive drug resistance patterns except for only one isolate which showed a pan-resistance pattern (considering only the examined groups) (Table 3). The isolates were more sensitive to aminoglycoside, fluoroquinolones, and aminopenicillins/ $\beta$-lactamase inhibitor combination.

On the other hand, the Acinetobacter isolates had a remarkable resistance with most of them showing pan- and extensively drug resistance patterns (Table 4). Acinetobacter spp. had about $71-100 \%$ resistance rates to all tested antimicrobials, including carbapenems (100\%), extended-spectrum cephalosporins (86$100 \%$ ), fluoroquinolones (100\%), aminoglycosides (86$100 \%)$, folic acid synthesis inhibitor (86\%), glycylcyclines (100\%), and aminopenicillins/beta-lactamase inhibitor (71\%) (Table 4).

Table 5 presents the resistance pattern of all the remaining isolates which showed different degrees of resistance. Sample numbers 3 and 14 representing Pseudomonas luteola were shown as pan-drug resistant; however, all the remaining samples vary between multiand extensive drug-resistant (XDR). 
Table 1 Demographic data of VAP patients admitted to ICU of BSU Hospital

\begin{tabular}{|c|c|c|c|c|c|c|}
\hline & Age & Sex & Days of hospital stay & Days of ventilation & Cause of admission & VAP causative bacteria \\
\hline 1 & 63 & M & 25 & 10 & Liver cell failure & Klebsiella pneumonia \\
\hline 2 & 52 & M & 17 & 8 & Rupture spleen & Klebsiella pneumonia \\
\hline 3 & 55 & M & 20 & 13 & Urinary tract infection (UTI) & Acinetobacter Iwoffii \\
\hline 4 & 48 & M & 30 & 17 & Heart disease & Klebsiella pneumonia \\
\hline 5 & 33 & M & 13 & 5 & Trauma & Klebsiella pneumonia \\
\hline 6 & 68 & M & 24 & 12 & Trauma & Klebsiella pneumonia \\
\hline 7 & 42 & M & 10 & 4 & UTI & Moraxella group \\
\hline 8 & 70 & M & 15 & 8 & Diabetic ketoacidosis & Klebsiella pneumonia \\
\hline 9 & 38 & M & 26 & 14 & Liver cell failure & Klebsiella pneumonia \\
\hline 10 & 61 & M & 9 & 6 & Hypovolemic shock & Pseudomonas aeruginosa \\
\hline 11 & 46 & $\mathrm{~F}$ & 25 & 14 & Cardiogenic shock & Serratia odorifera \\
\hline 12 & 31 & M & 23 & 9 & Trauma & Klebsiella pneumonia \\
\hline 13 & 54 & $\mathrm{~F}$ & 30 & 15 & Brain disease & Klebsiella pneumonia \\
\hline 14 & 28 & $\mathrm{~F}$ & 17 & 7 & Trauma & Klebsiella pneumonia \\
\hline 15 & 70 & M & 18 & 10 & Liver cell failure & Sphinogobacterium thalpophilum \\
\hline 16 & 65 & M & 30 & 14 & UTI & Pseudomonas luteola \\
\hline 17 & 34 & M & 14 & 8 & Hyperkalemia & Moraxella group \\
\hline 18 & 80 & $\mathrm{~F}$ & 28 & 10 & Heart disease & Acinetobacter baumannii \\
\hline 19 & 66 & M & 22 & 14 & UTI & Escherichia coli \\
\hline 20 & 34 & M & 12 & 5 & Trauma & Klebsiella pneumonia \\
\hline 21 & 50 & M & 25 & 15 & Trauma & Acinetobacter baumannii \\
\hline 22 & 62 & $\mathrm{~F}$ & 20 & 8 & Eclampsia & Klebsiella pneumonia \\
\hline 23 & 58 & M & 28 & 15 & Hypertensive shock & Klebsiella pneumonia \\
\hline 24 & 69 & M & 30 & 14 & Cardiogenic shock & Acinetobacter Iwoffii \\
\hline 25 & 48 & M & 28 & 10 & Liver cell failure & Klebsiella pneumonia \\
\hline 26 & 60 & M & 16 & 7 & UTI & Enterobacter aerogenes \\
\hline 27 & 72 & $\mathrm{~F}$ & 24 & 10 & Diabetic ketoacidosis & Acinetobacter baumannii \\
\hline 28 & 68 & M & 33 & 17 & Brain disease & Klebsiella pneumonia \\
\hline 29 & 40 & M & 10 & 4 & Trauma & Klebsiella pneumonia \\
\hline 30 & 29 & $\mathrm{~F}$ & 19 & 6 & Eclampsia & Klebsiella pneumonia \\
\hline 31 & 64 & M & 17 & 10 & Heart disease & Acinetobacter haemolyticus \\
\hline 32 & 40 & M & 14 & 8 & Trauma & Klebsiella pneumonia \\
\hline 33 & 70 & $\mathrm{~F}$ & 20 & 9 & UTI & Pseudomonas aeruginosa \\
\hline 34 & 54 & M & 10 & 6 & Epilepsy & Acinetobacter baumannii \\
\hline 35 & 80 & M & 30 & 15 & Liver cell failure & Klebsiella pneumonia \\
\hline 36 & 26 & $\mathrm{~F}$ & 13 & 8 & Eclampsia & Enterobacter aerogenes \\
\hline 37 & 55 & M & 20 & 9 & Diabetic ketoacidosis & Klebsiella pneumonia \\
\hline 38 & 35 & M & 10 & 6 & Trauma & Klebsiella pneumonia \\
\hline 39 & 44 & M & 7 & 5 & UTI & Pseudomonas putida \\
\hline 40 & 74 & M & 30 & 18 & Liver cell failure & Moraxella group \\
\hline 41 & 67 & M & 15 & 8 & Kidney disease & Sphinogobacterium paucimobilis \\
\hline 42 & 65 & M & 35 & 14 & Brain disease & Klebsiella pneumonia \\
\hline 43 & 71 & M & 10 & 4 & UTI & Sphinogobacterium thalpophilum \\
\hline 44 & 60 & M & 30 & 17 & Kidney failure & Acinetobacter baumannii \\
\hline
\end{tabular}


Table 1 Demographic data of VAP patients admitted to ICU of BSU Hospital (Continued)

\begin{tabular}{|c|c|c|c|c|c|c|}
\hline & Age & Sex & Days of hospital stay & Days of ventilation & Cause of admission & VAP causative bacteria \\
\hline 45 & 51 & M & 20 & 13 & Diabetic ketoacidosis & Klebsiella pneumonia \\
\hline 46 & 46 & M & 36 & 21 & Rupture spleen & Moraxella group \\
\hline 47 & 57 & $\mathrm{~F}$ & 18 & 7 & Diabetic ketoacidosis & Klebsiella pneumonia \\
\hline 48 & 35 & $\mathrm{~F}$ & 30 & 10 & Eclampsia & Klebsiella pneumonia \\
\hline 49 & 78 & $\mathrm{~F}$ & 16 & 9 & Liver cell failure & Pasteurella canis \\
\hline 50 & 62 & $\mathrm{~F}$ & 12 & 5 & Kidney disease & Klebsiella oxytoca \\
\hline 51 & 54 & $\mathrm{~F}$ & 30 & 20 & Liver cell failure & Brevundimonas diminyta/vesicularis \\
\hline 52 & 42 & $\mathrm{~F}$ & 28 & 10 & Pulmonary disease & Klebsiella pneumonia \\
\hline 53 & 49 & F & 20 & 8 & Rupture spleen & Pasteurella canis \\
\hline 54 & 65 & $\mathrm{~F}$ & 20 & 9 & Diabetic ketoacidosis & Pseudomonas luteola \\
\hline 55 & 80 & $\mathrm{~F}$ & 21 & 7 & UTI & Moraxella group \\
\hline 56 & 71 & $\mathrm{~F}$ & 26 & 12 & Eclampsia & Enterobacter aerogenes \\
\hline 57 & 66 & $\mathrm{~F}$ & 24 & 8 & Brain disease & Klebsiella pneumonia \\
\hline 58 & 57 & $\mathrm{~F}$ & 30 & 16 & Diabetic ketoacidosis & Acinetobacter baumannii \\
\hline 59 & 56 & $\mathrm{~F}$ & 24 & 13 & Cardiogenic shock & Klebsiella pneumonia \\
\hline 60 & 43 & $\mathrm{~F}$ & 40 & 17 & Trauma & Acinetobacter baumannii \\
\hline
\end{tabular}

Table 2 Gender distribution among BSU Hospital VAP cases

\begin{tabular}{|c|c|c|c|}
\hline \multicolumn{2}{|l|}{ Factor } & Male & Female \\
\hline \multicolumn{2}{|l|}{ No. of cases } & $37(61.6 \%)$ & $23(38.3 \%)$ \\
\hline \multicolumn{2}{|l|}{ Age range } & $30-80$ & $25-80$ \\
\hline \multicolumn{2}{|c|}{ Mean age of the patients } & 54.83 & 23.26 \\
\hline \multicolumn{2}{|l|}{ SD of age of patient } & 8.404 & 6.524 \\
\hline \multicolumn{2}{|c|}{ Mean of duration of ventilation/days } & 10 & 9 \\
\hline \multirow[t]{12}{*}{ Cause of admission } & Liver cell failure & $16.2 \%$ & $8.6 \%$ \\
\hline & Rupture spleen & $5.4 \%$ & $4.3 \%$ \\
\hline & Diabetic ketoacidosis & $8.1 \%$ & $13 \%$ \\
\hline & Eclampsia & $0 \%$ & $21.7 \%$ \\
\hline & Trauma & $18.9 \%$ & $8.6 \%$ \\
\hline & Brain disease & $5.4 \%$ & $8.6 \%$ \\
\hline & Kidney disease/failure & $8.1 \%$ & $4.3 \%$ \\
\hline & Cardiogenic shock & $2.7 \%$ & $8.6 \%$ \\
\hline & Heart disease & $10.8 \%$ & $4.3 \%$ \\
\hline & Pulmonary disease & $0 \%$ & $4.3 \%$ \\
\hline & Urinary tract infection & $16.2 \%$ & $8.6 \%$ \\
\hline & Hypovolemic shock & $2.7 \%$ & $0 \%$ \\
\hline \multicolumn{2}{|l|}{ Died } & \multicolumn{2}{|l|}{$25(41.7 \%)$} \\
\hline \multicolumn{2}{|l|}{ Survived } & \multicolumn{2}{|l|}{$35(58.3 \%)$} \\
\hline
\end{tabular}

\section{Discussion}

Oxygen which our cells need to operate comes from the outside environment and is exchanged with carbon dioxide in our respiratory system. The lungs are the place where gas exchange takes place. The lungs are especially helpless to disease since they are associated with the exterior environment that contains irresistible or poisonous species. When the lung alveoli are inflamed or infected, pneumonia occurs, which is known as the "captain of the men of death" as described by Dr. William Osler, the founder of modern medicine [18].

Despite extensive strategies for managing and decreasing VAP incidence, it remains to be the main cause of most deaths in patients with nosocomial infections [19]. This is in agreement with other studies reporting that lower respiratory tract infection is the major cause of death among different nosocomial infections $[20,21]$. The overall incidence rate of VAP in ICUs ranged from 10 to $70 \%$ as reported in a review article by Krishnamurthy et al. [22], indicating that different factors might contribute to the development of VAP. In the present study, the incidence rate of VAP was around 28\% (60 patients of a total of 213 patients).

Different factors were reported to increase the probability of VAP. Intubation is considered the most common cause for developing nosocomial pneumonia [23], 


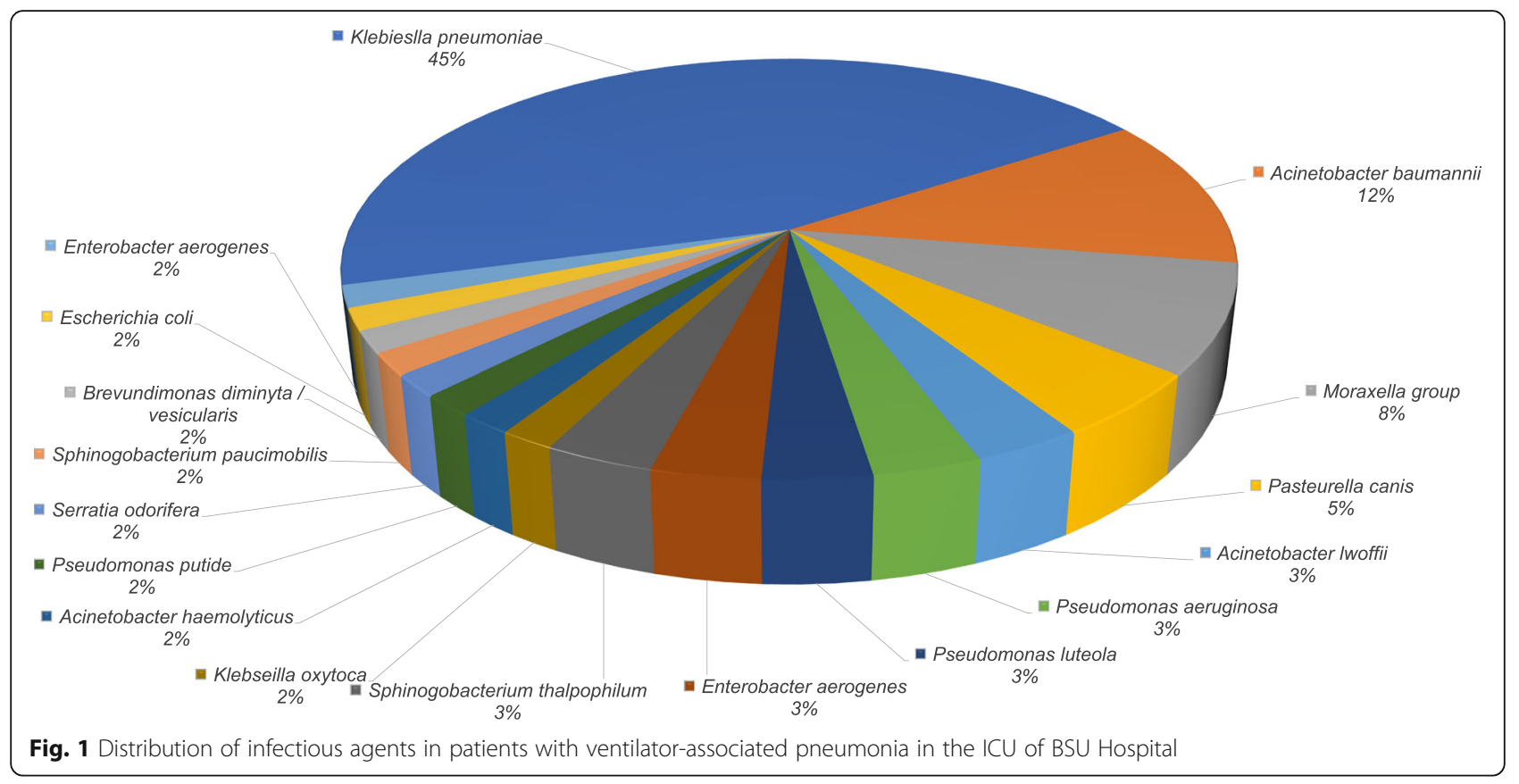

Table 3 Antibiotic resistance pattern among the different Klebsiella isolates

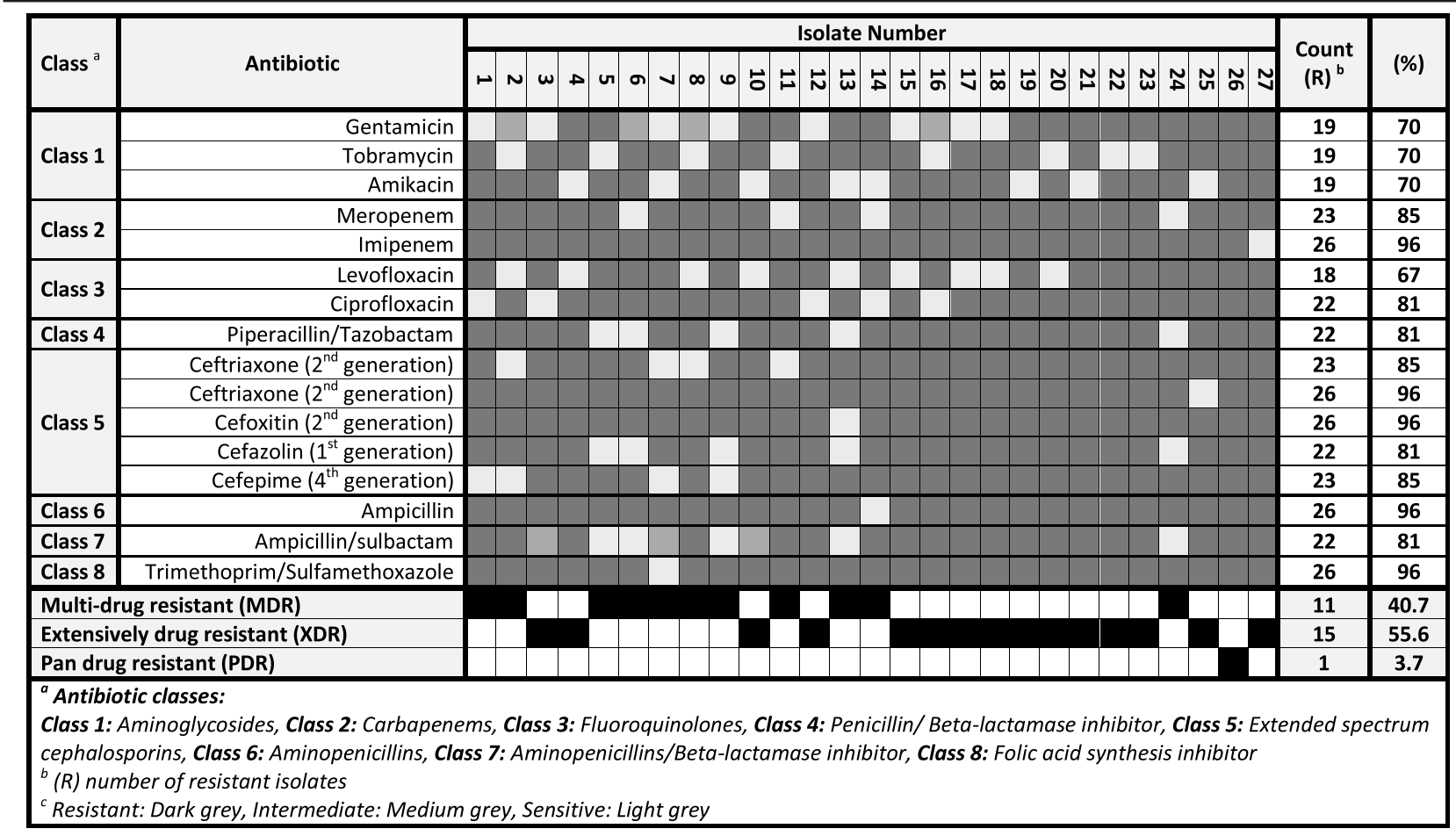

Resistant, dark gray; intermediate, medium gray; sensitive, light gray

antibiotic classes: class 1, aminoglycosides; class 2, carbapenems; class 3, fluoroquinolones; class 4, penicillin/beta-lactamase inhibitor; class 5, extended-spectrum cephalosporins; class 6, aminopenicillins; class 7, aminopenicillins/beta-lactamase inhibitor; and class 8 , folic acid synthesis inhibitor

${ }^{\mathrm{b}} R$ number of resistant isolates 
Table 4 Antibiotic resistance pattern among the different Acinetobacter isolates

\begin{tabular}{|c|c|c|c|c|c|c|c|c|c|c|}
\hline \multirow{2}{*}{ Class $^{a}$} & \multirow{2}{*}{ Antibiotic } & \multicolumn{7}{|c|}{ Isolate Number } & \multirow{2}{*}{$\begin{array}{c}\text { Count } \\
\text { (R) }\end{array}$} & \multirow{2}{*}{ (\%) } \\
\hline & & 1 & 2 & 3 & 4 & 5 & 6 & 7 & & \\
\hline \multirow{2}{*}{ Class 1} & Gentamicin & & & & & & & & 6 & 86 \\
\hline & Tobramycin & & & & & & & & 7 & 100 \\
\hline \multirow{2}{*}{ Class 2} & Meropenem & & & & & & & & 7 & 100 \\
\hline & Imipenem & & & & & & & & 7 & 100 \\
\hline Class 3 & Ciprofloxacin & & & & & & & & 7 & 100 \\
\hline \multirow{3}{*}{ Class 4} & Cefazolin ( $1^{\text {st }}$ generation $)$ & & & & & & & & 6 & 86 \\
\hline & Cefepime ( $4^{\text {th }}$ generation) & & & & & & & & 7 & 100 \\
\hline & Ceftriaxone ( $2^{\text {nd }}$ generation $)$ & & & & & & & & 6 & 86 \\
\hline Class 5 & Ampicillin/sulbactam & & & & & & & & 5 & 71 \\
\hline Class 6 & Trimethoprim/Sulfamethoxazole & & & & & & & & 7 & 100 \\
\hline \multirow[t]{4}{*}{ Class 7} & Tigecycline & & & & & & & & 6 & 86 \\
\hline & Multi Drug Resistance (MDR) & & & & & & & & 0 & 0 \\
\hline & Extensive-drug resistant (XDR) & & & & & & & & 4 & 57 \\
\hline & Pan-drug resistant (PDR) & & & & & & & & 3 & 43 \\
\hline \multicolumn{11}{|c|}{$\begin{array}{l}{ }^{a} \text { Antibiotic classes: } \\
\text { Class 1: Aminoglycosides, Class 2: Carbapenems, Class 3: Fluoroquinolones, Class 4: Extended } \\
\text { spectrum cephalosporins, Class 5: Aminopenicillins/Beta-lactamase inhibitor, Class 6: } \\
\text { Glycylcyclines, Class 7: Folic acid synthesis inhibitor } \\
{ }^{b} \text { (R) number of resistant isolates } \\
{ }^{C} \text { Resistant: Dark grey, Intermediate: Medium grey, Sensitive: Light grey }\end{array}$} \\
\hline
\end{tabular}

Resistant, dark gray; intermediate, medium gray; sensitive, light gray

${ }^{a}$ Antibiotic classes: class 1, aminoglycosides; class 2, carbapenems; class 3, fluoroquinolones; class 4, extended-spectrum cephalosporins; class 5, aminopenicillins/ beta-lactamase inhibitor; class 6 , glycylcyclines; and class 7, folic acid synthesis inhibitor

${ }^{\mathrm{b}} R$ number of resistant isolates

besides the aspiration of infected secretions from the oropharynx [24]. In the present study, most VAP cases were males probably due to smoking habits which is culturally predominant between males than females. This comes in agreement with previous studies which reported that smoker patients and those with underlying lung diseases, including chronic obstructive pulmonary disease (COPD), cystic fibrosis, congestive heart failure, and lung cancer, are more vulnerable to VAP owing to abnormalities in the lung structure and function [25].

The organisms causing VAP vary according to case mix, prior antibiotic exposure, the length of stay in the ICU, length of mechanical ventilation, patient characteristics, clinical circumstances, and geographic location (even between units in the same hospital) which emphasize the need for local epidemiological and microbiological evaluation [26]. Regarding the results of the present study, the most common microorganisms isolated from VAP cases were Gram-negative bacilli.
Surprisingly, no infections were recorded based on Gram-positive isolates, indicating that probably, the antibiotic regime used as a rule of thumb in the ICU and the cleaning protocols diminishes the possibility of their growth. Similar results were recently reported in the pediatric intensive care unit of King Abdulaziz Medical City, Saudi Arabia, during the evaluation of the VAP prevention bundle [27]. The prevention bundle included elevating the bed's head to avoid aspiration of oropharynx secretions, providing mouth hygiene to reduce oropharynx colonization, keeping ventilator circuits clean and dry to reduce device contamination, hand washing before and after touching the patients, using a cuffed endotracheal tube to avoid aspiration of oropharynx secretions, sedation holiday for deeply sedated patients every morning, and using anti-reflex prophylaxis. This resulted in the omission of Gram-positive bacteriamediated VAP [27]. Other studies at Egyptian Nasser Institute's ICU [28], Saudi Arabian King Abdul-Aziz 
Table 5 Antibiotic resistance pattern among the different other different isolates

\begin{tabular}{|c|c|c|c|c|c|c|c|c|c|c|c|c|c|c|c|c|}
\hline \multirow[t]{2}{*}{ Class $^{a}$} & \multirow[t]{2}{*}{ Antibiotic } & \multicolumn{15}{|c|}{ Isolate Number } \\
\hline & & -1 & $\mathbf{N}$ & $m$ & $\theta$ & in & 6 & $\wedge$ & $\infty$ & $a$ & 옥 & $\exists$ & $\mathcal{Y}$ & $\stackrel{m}{\rightarrow}$ & $\vec{A}$ & $\stackrel{\sim}{\sim}$ \\
\hline \multirow{3}{*}{ Class 1} & Gentamicin & & & & & & & & & & & & & & & \\
\hline & Topramycin & & & & & & & & & & & & & & & \\
\hline & Amikacin & & & & & & & & & & & & & & & \\
\hline Class 2 & Meropenem & & & & & & & & & & & & & & & \\
\hline \multirow{2}{*}{ Class 3} & Levofloxacin & & & & & & & & & & & & & & & \\
\hline & Ciprofloxacin & & & & & & & & & & & & & & & \\
\hline Class 4 & Piperacillin/Tazobactam & & & & & & & & & & & & & & & \\
\hline \multirow{4}{*}{ Class 5} & Ceftriaxone ( $2^{\text {nd }}$ generation) & & & & & & & & & & & & & & & \\
\hline & Ceftazidime ( $2^{\text {nd }}$ generation) & & & & & & & & & & & & & & & \\
\hline & Cefazolin ( $1^{\text {st }}$ generation $)$ & & & & & & & & & & & & & & & \\
\hline & Cefepime $\left(4^{\text {th }}\right.$ generation $)$ & & & & & & & & & & & & & & & \\
\hline Class 6 & Trimethoprim/Sulfamethoxazole & & & & & & & & & & & & & & & \\
\hline \multicolumn{17}{|c|}{ Multi-drug resistant (MDR) } \\
\hline \multicolumn{17}{|c|}{ Extensive-drug resistant (XDR) } \\
\hline \multicolumn{17}{|c|}{ Pan-drug resistant (PDR) } \\
\hline \multicolumn{17}{|c|}{$\begin{array}{l}\text { 'Antibiotic classes: } \\
\text { Class 1: Aminoglycosides, Class 2: Carbapenems, Class 3: Fluoroquinolones, Class 4: Penicillin/ Beta-lactamase inhibitor, Class 5: Extended } \\
\text { spectrum cephalosporins, Class 6: Folic acid synthesis inhibitor } \\
\text { b (R) number of resistant isolates } \\
{ }^{c} \text { Resistant: Dark grey, Intermediate: Medium grey, Sensitive: Light grey }\end{array}$} \\
\hline \multicolumn{17}{|c|}{$\begin{array}{l}\text { Isolate number: } \\
1,5,8,11,15: \text { Moraxella gro }\end{array}$} \\
\hline
\end{tabular}

Resistant, dark gray; intermediate, medium gray; sensitive, light gray

Isolate number: 1, 5, 8, 11, and 15-Moraxella group; 2 and 6-Pseudomonas aeruginosa; 3 and 10-Sphinogobacterium thalpophilum; 4 and 13-Pseudomonas luteola; 7 and 14-Enterobacter aerogenes; 9-Sphinogobacterium Paucimobilis; 12-Brevundimonas diminyta/vesicularis

$R$ number of resistant isolates

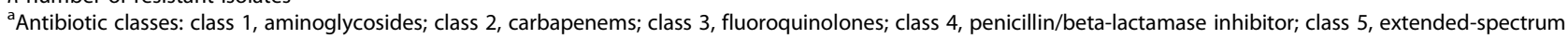
cephalosporins; and class 6, folic acid synthesis inhibitor

Medical City in Riyadh [29], and ICUs of different hospitals in an urban town in India [22] showed a higher rate of Gram-negative bacteria than Gram-positive ones.

Among the isolated Gram-negative bacilli, Klebsiella were the most common, followed by Acinetobacter and Pseudomonas. This agrees with a previous study conducted by Kanafani et al. [30] who have reported similar results for the VAP pathogen. Klebsiella spp., especially Klebsiella pneumoniae, are among the most common opportunistic nosocomial pathogens, ranked third with regard to drug-resistant infections in hospitals [31]. The digestive tract of ICU patients, the hands of the nursing staff, and the unclean endotracheal tube are considered the most significant reservoir of VAP pathogens [32].

On the other hand, core pathogens of VAP were different in several studies. K. pneumoniae was responsible for only a small fraction of VAP infections among ICU patients in Pakistani Clinic representing only $6.6 \%$, while MRSA was the main pathogen (40\% of VAP cases) [33]. In a different study conducted to correlate the VAP cases and causative organisms, Rello (2004) [34] reported that $H$. influenza and $M$. catarrhalis were the main findings in COPD patients, and $P$. aeruginosa and $S$. aureus were predominant in patients with cystic fibrosis, while $S$. aureus was the core pathogen in the case of trauma and neurologic patients. Acinetobacter also remains to be one of the core pathogens causing deadly VAP. It was responsible for most of the VAP cases in King Abdelaziz Medical City (KAMC) in Riyadh, Saudi Arabia [35].

Moreover, the antibiotic resistance aggravates the situation. The high rates of microbial resistance reported in the different studies are terrifying. Klebsiella pneumoniae, the causative agent of VAP in this study, was resistant to multiple antibiotics the same as the results of the study of Hudson et al. [36]. Klebsiella species with the ability to produce extended-spectrum $\beta$-lactamases (ESBL) are resistant to virtually all $\beta$-lactam antibiotics, except carbapenems. Other frequent resistance targets include aminoglycosides, fluoroquinolones, tetracyclines, chloramphenicol, and trimethoprim/sulfamethoxazole also similar to the study of Nathisuwan et al. [37].

A study conducted to evaluate the device-associated infection at Cairo University Hospital reported that 
around $70 \%$ of tested E. coli and K. pneumoniae isolates produced extended-spectrum $\beta$-lactamases [38]. In the USA, around $20 \%$ of $E$. coli and K. pneumoniae VAP isolates had extended-spectrum cephalosporin resistance. Resistance rates for other organisms are also substantially higher in Egypt. For instance, 100\% of Acinetobacter spp. isolates from hospital-acquired infections in Egypt are MDR versus approximately $70 \%$ of isolates in the NHSN; 93\% of S. aureus isolates tested in Egypt were methicillin-resistant compared with $50 \%$ in the NHSN [39].

\section{Conclusions}

VAP is an extreme infection that has to be managed as early as possible. The association of VAP with the multi, extensive-, and pan-drug-resistant bacteria specially for patients admitted to the ICUs is alarming and resulting in a considerable medical problem worldwide. As a result, the World Health Organization (WHO) has released an alarming infographic in 2014 motivating the researchers and companies to develop novel antimicrobials preparing for the post-antibiotic era. Different strategies are under investigation worldwide including bacteriophages, phage-derived proteins, bacteriocins, and metabolomics-based antibiotic mining, among others.

\section{Acknowledgements}

The authors would like to acknowledge Dr. Ahmed Farag Azmy, Department of Microbiology and Immunology, for his support during the sample collection stage.

\section{Authors' contributions}

ZM: sampling, performing the experiments, data analysis, preparing the first draft of the manuscript. WB: supervision and revision of the manuscript. YG: supervision, data analysis, and revision of the manuscript. TD:

conceptualization, supervision, data analysis, and preparing and revising the manuscript. All authors have read and approved the final manuscript.

\section{Funding}

None.

\section{Availability of data and materials}

The datasets used and/or analyzed during the current study are available from the corresponding author on reasonable request.

\section{Declarations}

Ethics approval and consent to participate

The Research Ethical Committee of Faculty of Pharmacy, Beni-Suef University, has given the approval on conducting the present research (Approval serial no.: REC-H-PhBSU-21012).

\section{Consent for publication}

The informed consent was obtained verbally since VAP patients are under mechanical ventilation in the intensive care unit for more than $48 \mathrm{~h}$. VAP patients are suffering from pneumonia leading to difficulty breathing. Therefore, approval for a verbal consent was requested and approved. The study was conducted on residual samples (sputum) that were collected as routine work by the critical care physicians using traditional techniques without any modification.

\section{Competing interests}

The authors declare that they have no competing interests.

\section{Author details}

${ }^{1}$ Department of Microbiology and Immunology, Faculty of Pharmacy, Nahda University, Beni Suef, Egypt. Department of Microbiology and Immunology, Faculty of Pharmacy, Beni-Suef University, Beni Suef, Egypt. ${ }^{3}$ Department of Pharmaceutics and Pharmaceutical Technology, College of Pharmacy, Mutah University, Kerak 61710, Jordan.

Received: 19 June 2021 Accepted: 17 July 2021

Published online: 29 July 2021

\section{References}

1. Kollef MH (1999) The prevention of ventilator-associated pneumonia. N Engl J Med 340(8):627-634. https://doi.org/10.1056/NEJM199902253400807

2. Zack JE, Garrison T, Trovillion E, Clinkscale D, Coopersmith CM, Fraser VJ, Kollef $\mathrm{MH}$ (2002) Effect of an education program aimed at reducing the occurrence of ventilator-associated pneumonia. Crit Care Med 30(11):24072412. https://doi.org/10.1097/00003246-200211000-00001

3. Trouillet J-L, Chastre J, Vuagnat A, Joly-Guillou M-L, Combaux D, Dombret M-C, Gibert C (1998) Ventilator-associated pneumonia caused by potentially drug-resistant bacteria. Am J Respir Crit Care Med 157(2):531-539. https:// doi.org/10.1164/ajrccm.157.2.9705064

4. Craven DE (2000) Epidemiology of ventilator-associated pneumonia. Chest 117(4):186S-187S. https://doi.org/10.1378/chest.117.4_suppl_2.186S

5. Rello J, Torres A (1996) Microbial causes of ventilator-associated pneumonia. In: Seminars in respiratory infections, pp 24-31

6. American_Thoracic_Society (1996) Hospital-acquired pneumonia in adults: diagnosis, assessment of severity, initial antimicrobial therapy, and preventive strategies. A consensus statement, American Thoracic Society, November 1995. Am J Respir Crit Care Med 153(5):1711-1725. https://doi. org/10.1164/ajrccm.153.5.8630626

7. Morehead RS, Pinto SJ (2000) Ventilator-associated pneumonia. Arch Intern Med 160(13):1926-1936. https://doi.org/10.1001/archinte.160.13.1926

8. De Rosa FG (2003) Ventilator-associated pneumonia: current management strategies. Inf Med 20:248-259

9. Ryan JF, Newman A, Jacobs M (2000) The pharmaceutical century: ten decades of drug discovery, vol 53. ACS, Washington, DC

10. Nicastro J, Wong S, Khazaei Z, Lam P, Blay J, Slavcev RA (2016) Bacteriophage applications-historical perspective and future potential. Springer International Publishing (Cham, Switzerland). https://doi.org/10.1 007/978-3-319-45791-8

11. Reuter M, Kruger DH (2020) Approaches to optimize therapeutic bacteriophage and bacteriophage-derived products to combat bacterial infections. Virus Genes 56(2):136-149. https://doi.org/10.1007/s11262-020-01 735-7

12. Horan TC, Andrus M, Dudeck MA (2008) CDC/NHSN surveillance definition of health care-associated infection and criteria for specific types of infections in the acute care setting. Am J Infect Control 36(5):309-332. https://doi.org/10.1016/j.ajic.2008.03.002

13. Pincus DH (2006) Microbial identification using the bioMérieux Vitek ${ }^{\oplus}$ system. Encyclopedia of Rapid Microbiological Methods. Parenteral Drug Association, Bethesda, pp 1-32

14. Hogan J, Smith KL (2003) Coliform mastitis. Vet Res 34(5):507-519. https:// doi.org/10.1051/vetres:2003022

15. Wayne PA (2011) Clinical and laboratory standards institute. Performance standards for antimicrobial susceptibility testing

16. Ortmann AC, Suttle CA (2009) Determination of virus abundance by epifluorescence microscopy. In: Methods in Molecular Biology (501). Springer (Clifton, N.J.), pp 87-95. https://doi.org/10.1007/978-1-60327-1646_10

17. Tapsall JW, Ndowa F, Lewis DA, Unemo M (2009) Meeting the public health challenge of multidrug-and extensively drug-resistant Neisseria gonorrhoeae. Expert Rev Anti Infect Ther 7(7):821-834. https://doi.org/10.1586/eri.09.63

18. Osler W (1892) The principles and practice of medicine. D. Appleton and Company, New York Available at: https://archive.org/details/principlespra ct00osle/page/n7/mode/2up

19. Kollef MH (2005) What is ventilator-associated pneumonia and why is it important? Respir Care 50:714-724

20. Celis R, Torres A, Gatell JM, Almela M, Rodríguez-Roisin R (1988) Nosocomial pneumonia. A multivariate analysis of risk and prognosis. Chest 93(2):318324. https://doi.org/10.1378/chest.93.2.318 
21. Gross PA, Neu HC, Aswapokee P, Van Antwerpen C, Aswapokee N (1980) Deaths from nosocomial infections: experience in a university hospital and a community hospital. Am J Med 68(2):219-223. https://doi.org/10.1016/ 0002-9343(80)90357-5

22. Krishnamurthy V, Vijay Kumar GS, Prashanth HV, Prakash R, Kumar MS (2013) Ventilator associated pneumonia: bacterial isolates and its antibiotic resistance pattern. Int J Biol Med Res 4:3135-3138

23. Rello J, Diaz E (2003) Pneumonia in the intensive care unit. Crit Care Med 31(10):2544-2551. https://doi.org/10.1097/01.CCM.0000089928.84326.D2

24. Estes RJ, Meduri GU (1995) The pathogenesis of ventilator-associated pneumonia. Care Med 21:365-383

25. Hunter JD (2006) Ventilator associated pneumonia. Postgrad Med J 82(965): 172-178. https://doi.org/10.1136/pgmj.2005.036905

26. Park DR (2005) The microbiology of ventilator-associated pneumonia. Respir Care 50:742-765

27. Osman S, Al Talhi YM, AlDabbagh M, Baksh M, Osman M, Azzam M (2020) The incidence of ventilator-associated pneumonia (VAP) in a tertiary-care center: comparison between pre- and post-VAP prevention bundle. J Infect Public Health 13(4):552-557. https://doi.org/10.1016/j.jiph.2019.09.015

28. Abdel-Latif W (2013) The impact of improvement project on ventilato associated pneumonia incidence rate at Nasser Institute intensive care unit in Cairo. Egypt J Med Lab Sci 22:205-220

29. Al-Dorzi HM, El-Saed A, Rishu AH, Balkhy HH (2012) The results of a 6-year epidemiologic surveillance for ventilator-associated pneumonia at a tertiary care intensive care unit in Saudi Arabia. Am J Infect Control 40(9):794-799. https://doi.org/10.1016/j.ajic.2011.10.004

30. Kanafani Z, Kara L, Hayek S, Kanj S (2003) Ventilator-associated pneumonia at a tertiary-care center in a developing country: incidence, microbiology, and susceptibility patterns of isolated microorganisms. Infect Control Hosp Epidemiol 24(11):864-869. https://doi.org/10.1086/502151

31. Pendleton JN, Gorman SP, Gilmore BF (2013) Clinical relevance of the ESKAPE pathogens. Expert Rev Anti Infect Ther 11:297-308

32. Coovadia YM, Johnson AP, Bhana RH, Hutchinson GR, George RC, Hafferjee IE (1992) Multiresistant Klebsiella pneumoniae in a neonatal nursery: the importance of maintenance of infection control policies and procedures in the prevention of outbreaks. J Hosp Infect 22(3):197-205. https://doi.org/1 0.1016/0195-6701(92)90044-M

33. Ahmad S, Bacha N, Bakht J, Jawad A (2017) Characterization of pathogens involved in ventilator associated pneumonia in surgical and medical intensive care units: a single center experience. Pak J Pharm Sci 30(6):20912099

34. Rello J (2004) Bench-to-bedside review: therapeutic options and issues in the management of ventilator-associated bacterial pneumonia. Crit Care 9(3):1-7

35. Balkhy HH, El-Saed A, Maghraby R, Al-Dorzi HM, Khan R, Rishu AH, Arabi YM (2014) Drug-resistant ventilator associated pneumonia in a tertiary care hospital in Saudi Arabia. Ann Thorac Med 9(2):104-111. https://doi.org/10.41 03/1817-1737.128858

36. Hudson CM, Bent ZW, Meagher RJ, Williams KP (2014) Resistance determinants and mobile genetic elements of an NDM-1-encoding Klebsiella pneumoniae strain. PLoS One 9(6):e99209. https://doi.org/10.1371/ journal.pone.0099209

37. Nathisuwan S, Burgess DS, Lewis J (2001) Extended-spectrum $\beta$-lactamases: epidemiology, detection, and treatment. Pharmacotherapy 21(8):920-928. https://doi.org/10.1592/phco.21.11.920.34529

38. El-Kholy A, Saied T, Gaber M, Younan MA, Haleim MM, El-Sayed H (2012) Device-associated nosocomial infection rates in intensive care units at Cairo University Hospitals: first step toward initiating surveillance programs in a resource-limited country. Am J Infect Control 40(6):e216-e220. https://doi. org/10.1016/j.ajic.2011.12.010

39. Sievert DM, Ricks P, Edwards JR, Schneider A, Patel J, Srinivasan A, Kallen A, Limbago B, Fridkin S (2013) Antimicrobial-resistant pathogens associated with healthcare-associated infections: summary of data reported to the National Healthcare Safety Network at the Centers for Disease Control and Prevention. Infect Control Hosp Epidemiol 34(1):1-14. https://doi.org/10.1 086/668770

\section{Publisher's Note}

Springer Nature remains neutral with regard to jurisdictional claims in published maps and institutional affiliations.

\section{Submit your manuscript to a SpringerOpen ${ }^{\circ}$ journal and benefit from:}

- Convenient online submission

- Rigorous peer review

- Open access: articles freely available online

- High visibility within the field

- Retaining the copyright to your article

Submit your next manuscript at $\boldsymbol{\nabla}$ springeropen.com 